\title{
Pinostrobin attenuates colistin-induced apoptosis of human renal proximal tubular cells
}

\author{
Nichakorn Worakajit ${ }^{1}$, Penjai Thongnuanjan², Napason Chabang'3, \\ Sirima Soodvilai ${ }^{4}$, Patoomratana Tuchinda ${ }^{5}$, Sunhapas Soodvilai ${ }^{1,5^{*}}$ \\ 1 Research Center of Transporter Protein for Medical Innovation, Department of Physiology, Faculty of Science, Mahidol University, Bangkok, Thailand \\ 2 Toxicology Graduate Program, Multidisciplinary Unit, Faculty of Science, Mahidol University, Bangkok, Thailand \\ 3 School of Bioinnovation and Bio-based Product Intelligence, Faculty of Science, Mahidol University, Bangkok, Thailand \\ 4 Department of Pharmaceutical Technology, Faculty of Pharmacy, Rangsit University, Pathumthani, Thailand \\ 5 Excellent Center for Drug Discovery, Mahidol University, Bangkok, Thailand
}

\section{ABSTRACT}

Colistin is one of the last-resort antibiotics used to treat multidrug-resistant (MDR) gram-negative bacterial infection. However, this drug causes nephrotoxicity by inducing oxidative stress and mitochondrial impairment of renal proximal tubular cells. Pinostrobin, which is a major natural bioactive compound isolated from Boesenbergia rotunda, has anti-oxidative properties and preventive effects on mitochondrial damage. Therefore, this study aimed to investigate the protective effects of pinostrobin against colistin-induced toxicity in human renal proximal tubular (RPTEC/TERT1) cells. Treatment of colistin $(200 \mu \mathrm{g} / \mathrm{ml})$ significantly reduced cell viability and increased apoptotic cells compared with vehicle treatment. These effects were attenuated by cotreatment with pinostrobin $(50-100 \mu \mathrm{M})$. Colistin-induced apoptosis was correlated with increased ROS and cytochrome c expression accompanied by reduction in mitochondrial membrane potential and anti-apoptotic protein (Bcl-2) expression. These effects were abolished by co-treatment with pinostrobin. Collectively, pinostrobin has protective effects against colistin-induced apoptosis of RPTEC/TERT1 cells by improving oxidative status and mitochondrial function.

\section{Keywords:}

Colistin, Mitochondrial dysfunction, Nephrotoxicity, Pinostrobin, Renal proximal tubular cell

\section{INTRODUCTION}

Drug-induced nephrotoxicity, particularly in acute kidney injury (AKI), represents the most complication associated with treatment of the particular diseases. The common pathophysiology of these diseases including glomerular hemodynamic alterations, crystal formation, inflammation, and tubular cell toxicity ${ }^{1-3}$. An approximate 50-60\% of drug-related AKI was caused by antibiotics and anti-inflammatory drugs ${ }^{4,5}$.

Among antibiotics, colistin (or polymyxin E) represents the most important drug possessing nephrotoxicity as an adverse effect ${ }^{6}$. In the clinical settings, this drug is a last-line polypeptide antibiotic for the treatment of Gram-negative bacterial infection caused by MDR ${ }^{7}$. Moreover, colistin has been announced by World Health
Organization (WHO) to use as an essential drug for the treatment of severe infections particularly the diseases caused by Pseudomonas aeruginosa and Enterobacteriacea $^{8}$. However, the uses of colistin are associated with $\mathrm{AKI}^{9-10}$. Administration of colistin causes accumulation of this drug in renal proximal tubules which further induces oxidative stress, mitochondrial damage, activation of inflammatory processes, and cell death in both in vitro and in vivo studies ${ }^{9-15}$. These pathologic features lead to kidney injuries as indicated by decrease in creatinine clearance level and low urine output, and kidney failure ensues. However, there are no effective therapies to diminish adverse effect of colistin. Therefore, development of novel nephroprotective agents is very challenging and important for optimizing clinical use of colistin.

Pinostrobin is a dominant natural bioflavonoid

\section{*Corresponding author:}

*Sunhapas Soodvilai sunhapas.soo@mahidol.ac.th 
isolated from Boesenbergia rotunda, a ginger species located in Southeast Asia. This plant originally defined as a medicinal plant due to many pharmacological activities such as antioxidant against lipid peroxidation ${ }^{16}$, ${ }^{17}$, anti-inflammatory and anti-bacterial activities ${ }^{18}$. Study of Li et al., reveals that pinostrobin can suppress neurotoxin-induced neuronal cell apoptosis by altering intrinsic mitochondrial pathway ${ }^{19}$. Despite its prominent bioactivities, the nephroprotective effect of pinostrobin remains enigmatic. Therefore, this study aimed to investigate whether pinostrobin protects against renal cell apoptosis induced by colistin.

\section{MATERIALS AND METHODS}

\subsection{Chemicals and reagents}

Pinostrobin (purity $>98 \%$ by HPLC) was isolated from Boesenbergia rotunda. Colistin sulfate salt $(15,000$ units/mg), thiazolyl blue tetrazolium bromide (MTT) and trypan blue were purchased from Sigma-Aldrich (MO, USA). Apoptosis Detection Kit (Annexin V-FITC) was purchased from BD biosciences (CA, USA). Bcl-2, cytochrome $\mathrm{c}$, and $\beta$-actin antibody were purchased from Cell signaling Technology (MA, USA).

\subsection{Extraction and isolation of pinostrobin}

The air-dried and finely powdered rhizomes of B. rotunda $(2.5 \mathrm{~kg})$ were percolated with $95 \% \mathrm{EtOH}(6$ $\mathrm{L}, 4$ times $\mathrm{x} 7$ days) at room temperature to give a crude EtOH extract $(535.6 \mathrm{~g})$ after solvent removal. After addition of $\mathrm{EtOH}(1 \mathrm{~L})$ to the crude extract, the precipitate was filtered, washed with cold $\mathrm{EtOH}$ to obtain a crude solid (71.3 g) and a residue (res. 1) (460.4 g) after evaporation under reduced pressure. Recrystallization of the crude solid material from EtOH provided pure pinostrobin (26.6 g) and a residue (res. 2) (44.6 g) after evaporation under reduced pressure. The combined residue (res. 1+res. 2, $505 \mathrm{~g}$ ) were further separated by column chromatography on silica gel, eluting with EtOAc-hexanes gradient to afford six separated subfractions (A1-A6). Subfraction A3 (123.0 g) yielded an additional amount of pure pinostrobin $(41.2 \mathrm{~g})$ after crystallization from EtOH. A chemical structure of pinostrobin is shown in Figure 1A.

\subsection{Cell Culture}

RPTEC/TERT1 cells, a human renal proximal tubular cells line, were purchased from American Type Culture Collection (VA, USA). Cells were cultured in the mixture of Dulbecco's modified Eagle's medium with Ham's F-12 medium supplemented with $100 \mathrm{U} / \mathrm{ml}$ penicillin, $100 \mu \mathrm{g} / \mathrm{ml}$ streptomycin, $5 \mu \mathrm{g} / \mathrm{ml}$ human transferrin, $10 \mathrm{ng} / \mathrm{ml}$ recombinant human EGF, $25 \mathrm{ng} / \mathrm{ml}$ hydrocortisone, $0.05 \mu \mathrm{g} / \mathrm{ml}$ selenium and $5 \mu \mathrm{g} / \mathrm{ml}$ insulin. Cells were incubated at $37^{\circ} \mathrm{C}$ in $5 \% \mathrm{CO}_{2}$ under $95 \%$ humidity. Once confluent, RPTEC/TERT1 cells were collected with $0.25 \%$ Trypsin EDTA for 20-30 minutes. Cells were grown in culture plate until $100 \%$ cell confluence before further subsequent experimental procedures. The treatment protocol has been shown in Figure 1B.

\subsection{Cell viability assay}

Cell viability of RPTEC/TERT1 was detected by using MTT assay and trypan blue staining method. MTT assay was performed by washed the cells twice with serum-free media and replaced with $100 \mu \mathrm{l} /$ well of MTT solution $(0.5 \mathrm{mg} / \mathrm{ml})$ and incubated for $1 \mathrm{~h}$ in humidified atmosphere of $5 \% \mathrm{CO}_{2}$ at $37^{\circ} \mathrm{C}$. The supernatant was discarded, and $100 \mu \mathrm{l} /$ well of DMSO was added to dissolve formazan crystals. The absorbance was read at $570 \mathrm{~nm}$ using microplate reader. For trypan blue staining, the cell suspensions were stained with $0.4 \%$ trypan blue solution in buffer isotonic salt before observed under light microscope. Unstaining cells and staining cells indicated as live cells and dead cells, respectively.

\subsection{Determination of cell apoptosis}

Apoptotic cells were determined by flow cytometry assay following staining with propidium iodide (PI) and an annexin V-FITC. Harvested cells were suspended with $1 \mathrm{X}$ biding buffer and stained with Annexin V-FITC and PI in the dark for 15 minutes. The stained cells were subjected to flow cytometry analysis (BD Biosciences, CA, USA). The results were reported as the percentage of live cells, apoptosis cells and necrosis cells in the random sampling of 30,000 cells.

\subsection{Assessment of mitochondrial ROS production}

The level of intracellular ROS was determined using fluorescent reagent 2', '7'-dichlorofluorescin diacetate (DCFH-DA). RPTEC/TERT1 cells grown on 96-black well plate were washed with sterile DPBS and incubated with $10 \mu \mathrm{M}$ DCFH-DA for 30 minutes at $37^{\circ} \mathrm{C}, 5 \% \mathrm{CO}_{2}$ in the dark. After removed the dye, cells were three washed with sterile DPBS and photographed with 20X fluorescence microscope. The fluorescence absorbance was measured at excitation and emission wavelength 480 and $530 \mathrm{~nm}$ respectively using fluorescence plate reader (Operetta and EnVision, PerkinElmer). Relative ROS level was calculated as percentage normalized with control.

2.7. Assessment of the alteration in mitochondrial membrane potential $\left(\Delta \psi_{\mathrm{m}}\right)$ 
The change in mitochondrial membrane potential of RPTEC/TERT1 cells was measured using JC-1 fluorescence dye. The cells on 96-back well plate were washed with DPBS and then incubated with $20 \mu \mathrm{M}$ JC-1 reagent in DPBS for $15 \mathrm{~min}$ at $37^{\circ} \mathrm{C}$. Dye was removed, cells were washed again with DPBS and observed under fluorescence microscope at an emission wavelength of $488 \mathrm{~nm}$. Monomeric and aggregates forms of JC-1 were emitted green and red fluorescence at 530 and $595 \mathrm{~nm}$, respectively. Quantitative analysis of fluorescence intensity was measured by image $\mathbf{J}$ software. The ratios of red/green fluorescence intensity were interpreted as the alteration of mitochondrial membrane potential.

\subsection{Assessment of apoptotic proteins expression}

Total protein of RPTEC/TERT1 cells were extracted with lysis buffer $(100 \mu \mathrm{l} /$ well $)$ and incubated on ice for 20 minutes. Whole cell suspension was centrifuged at $13,000 \mathrm{rpm}$ at $4^{\circ} \mathrm{C}$ for 20 minutes. The supernatant was collected and stored at $-80^{\circ} \mathrm{C}$. An equal amount of protein samples was analyzed by Western blotting. Proteins were separated by $12 \%$ SDS-PAGE and transferred to nitrocellulose membranes. The membrane was blocked with nonfat dry milk (5\%) in Tris-buffered Saline-Tween 20 (TBST) for 2 hours before overnight incubation with primary antibodies. The membranes were washed with TBST, followed by secondary antibody (horseradish peroxidase-conjugated) incubation for 1 hour. Finally, the immune complexes were detected using Electro-Chemi-Luminescence (ECL) and exposed to UltraCruz autoradiography films (Santa Cruz, CA). The protein bands intensity was analyzed and quantified using Image $\mathbf{J}$ software.

\subsection{Data analysis and statistical methods}

All data are expressed as means \pm SEM. Figures were prepared using GraphPad Prism 5.0 (GraphPad Software, San Diego, CA, USA). The statistical significance between control and treatment groups was analyzed using one-way ANOVA followed by Tukey test for multigroup comparisons. A $P$ value $<0.05$ was considered significant difference.

\section{RESULTS}

\subsection{Pinostrobin attenuates colistin-induced toxicity in renal proximal tubular cells}

The protective effects of pinostrobin on colistininduced cellular toxicity were determined using MTT and trypan blue staining assays in RPTEC/TERT1 cells. As shown in Figure 2A, cell viability was reduced by increasing concentration of colistin with the $\mathrm{IC}_{50} \sim 200$ $\mu \mathrm{g} / \mathrm{mL}$ at $72 \mathrm{~h}$. Interestingly, this cytotoxicity was attenuated by co-treatment with pinostrobin in a concentration-dependent manner with maximal effect being observed at $50 \mu \mathrm{M}$ (Figure 2B). Similarly, the results were consistent with trypan blue staining method (Figure 2C). These results suggest protective effects of pinostrobin on colistin-induced proximal tubular cytotoxicity.

\subsection{Pinostrobin alleviates colistin-induced apoptostic cells death}

Colistin causes nephrotoxicity by induction of apoptosis. To determine whether pinostrobin protected proximal tubular cells against colistin-induced apoptosis,

Figure 1

A<smiles>COc1cc(O)c2c(c1)OC(c1ccccc1)CC2=O</smiles>

B

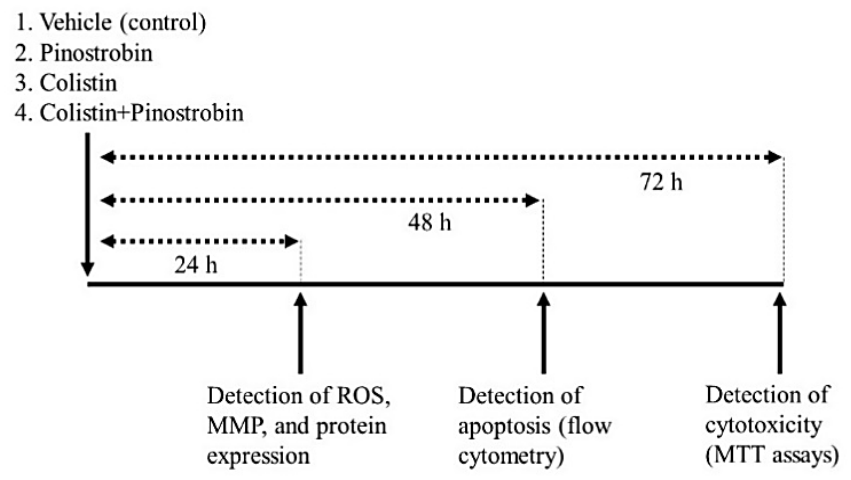

Figure 1. Chemical structure of pinostrobin (A) and experimental protocol (B). 
A

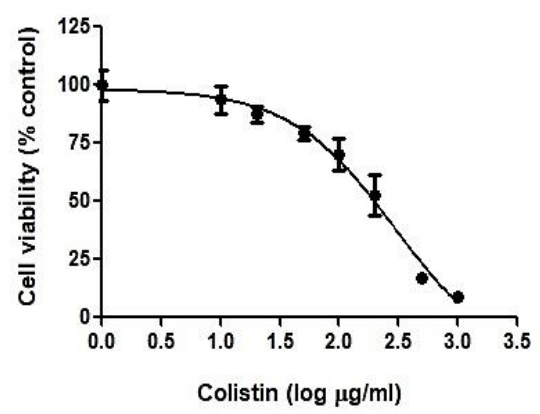

B

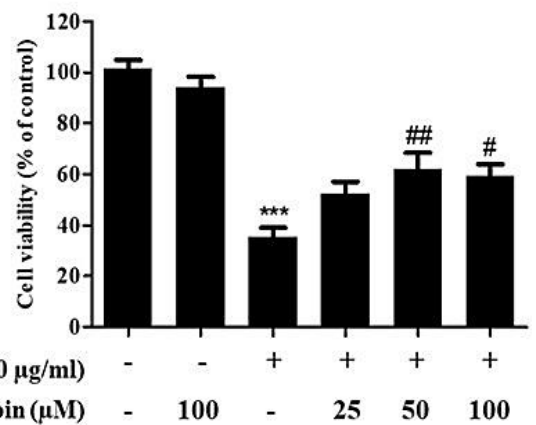

C

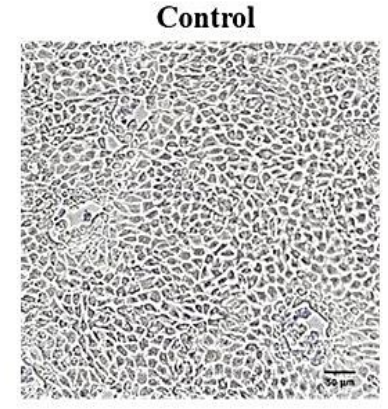

Colistin

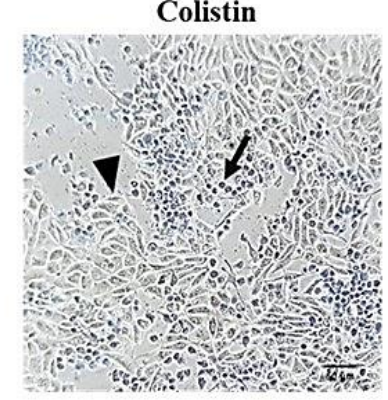

PS $100 \mu \mathrm{M}$

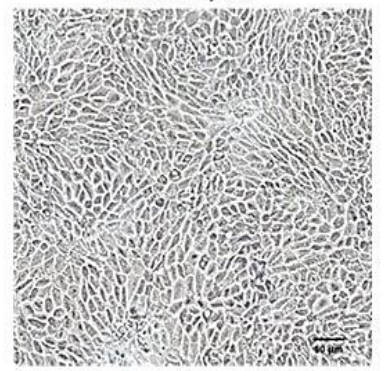

Colistin + PS $50 \mu M$

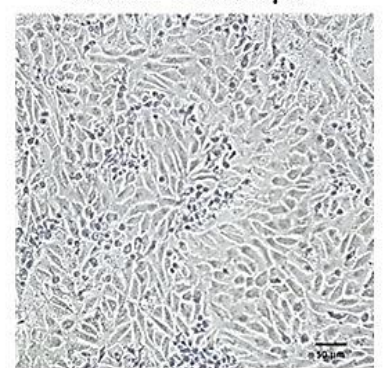

Figure 2. Effect of pinostrobin on cell viability after colistin exposure. (A) Concentration-response relationship of colistin on cytotoxicity at $72 \mathrm{~h}$ treatment as analyzed by MTT assays. (B) The viability of RPTEC/TERT1 cells after 72 hours treated with vehicle, $100 \mu \mathrm{M}$ pinostrobin, $200 \mu \mathrm{g} / \mathrm{ml}$ colistin, and $200 \mu \mathrm{g} /$ colistin plus 25,50 or $100 \mu \mathrm{M}$ pinostrobin. (C) Imaging of cells stained with trypan blue indicated dead cell (arrow) and live cell (triangle). The data are represented as mean \pm SEM of $\%$ control; $\mathrm{n}=3$. ${ }^{*} P<0.001$ compared with control, ${ }^{\#} P<0.05$ compared with colistin-treated group. PS represents pinostrobin.

$\mathbf{A}$

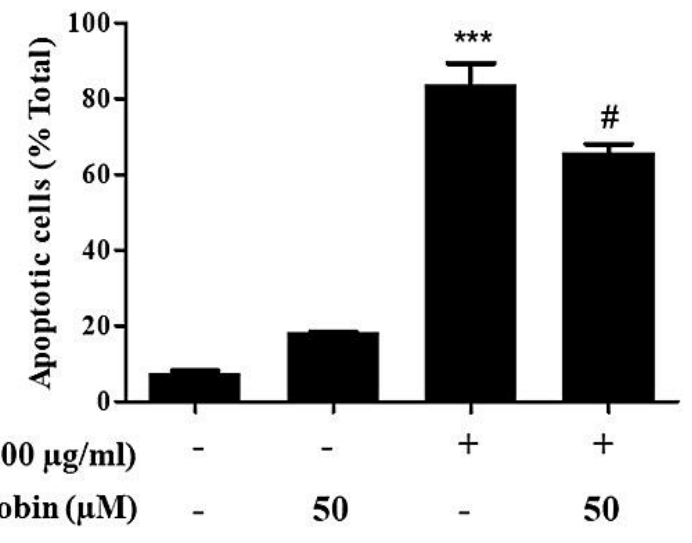

B
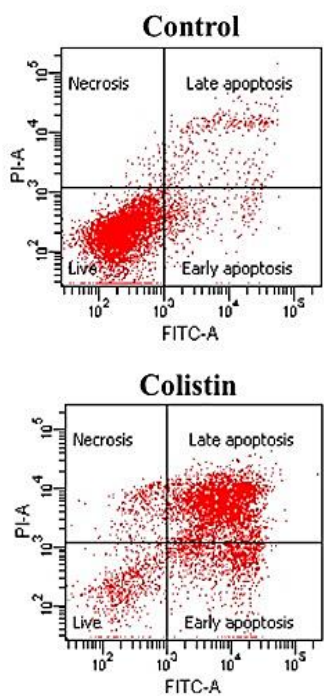

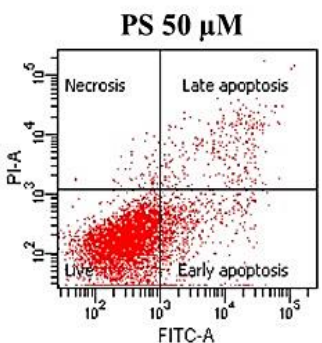

Colistin + PS $50 \mu \mathrm{M}$

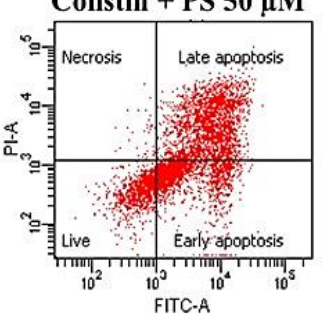

Figure 3. Effect of pinostrobin on apoptosis of RPTEC/TERT1 cells. Apoptotic cells were analyzed by flow cytometry after 48 hours of treatment with vehicle, $50 \mu \mathrm{M}$ pinostrobin, $200 \mu \mathrm{g} / \mathrm{ml}$ colistin and $200 \mu \mathrm{g} / \mathrm{ml}$ colistin plus $50 \mu \mathrm{M}$ pinostrobin. Data are shown as mean \pm SEM of $\%$ control: $\mathrm{n}=3$. ${ }^{*} P<0.001$ compared with control, ${ }^{\#} P<0.05$ compared with colistin-treated group. PS represents pinostrobin. 
A

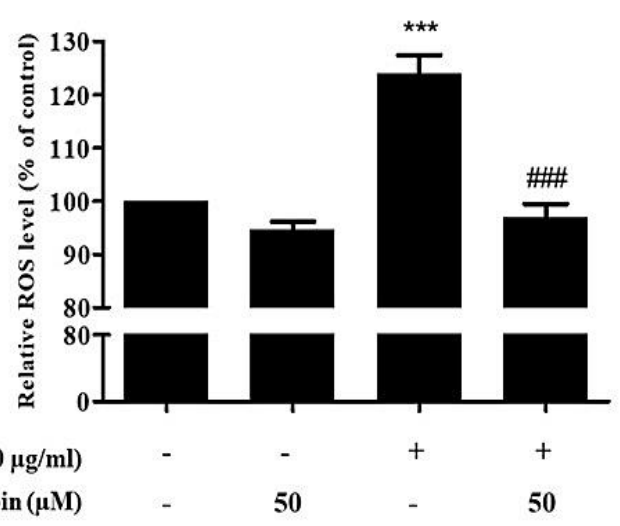

B

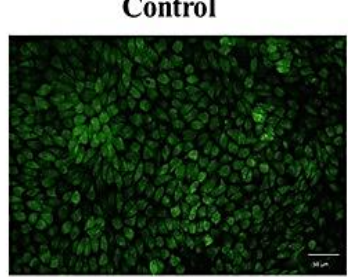

Colistin

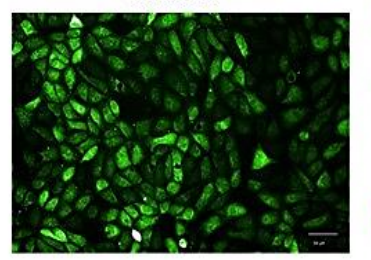

PS $50 \mu \mathrm{M}$

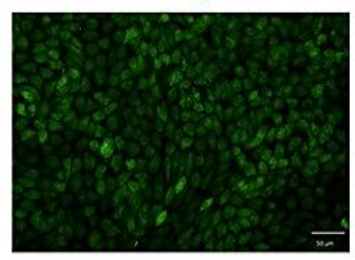

Colistin + PS $50 \mu \mathrm{M}$

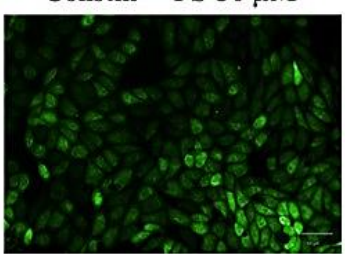

Figure 4. Effect of pinostrobin on colistin-stimulated ROS production in RPTEC/TERT1 cells. (A) Fluorescence imaging of ROS production in renal proximal tubular cells after $24 \mathrm{~h}$ incubated with vehicle, $200 \mu \mathrm{g} / \mathrm{ml}$ colistin and $200 \mu \mathrm{g} / \mathrm{ml}$ colistin plus $50 \mu \mathrm{M}$ pinostrobin. (B) Relative ROS levels for each condition compared with control. The data are represented as mean \pm SEM of $\%$ control form 4 experiments. ${ }^{*} P<0.001$ compared with control, ${ }^{\#} P<0.001$ compared with colistin-treated group. PS represents pinostrobin.

$\mathbf{A}$

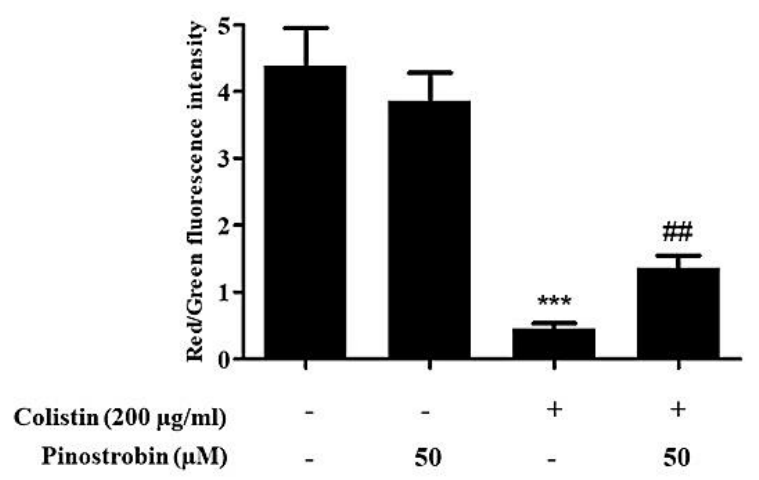

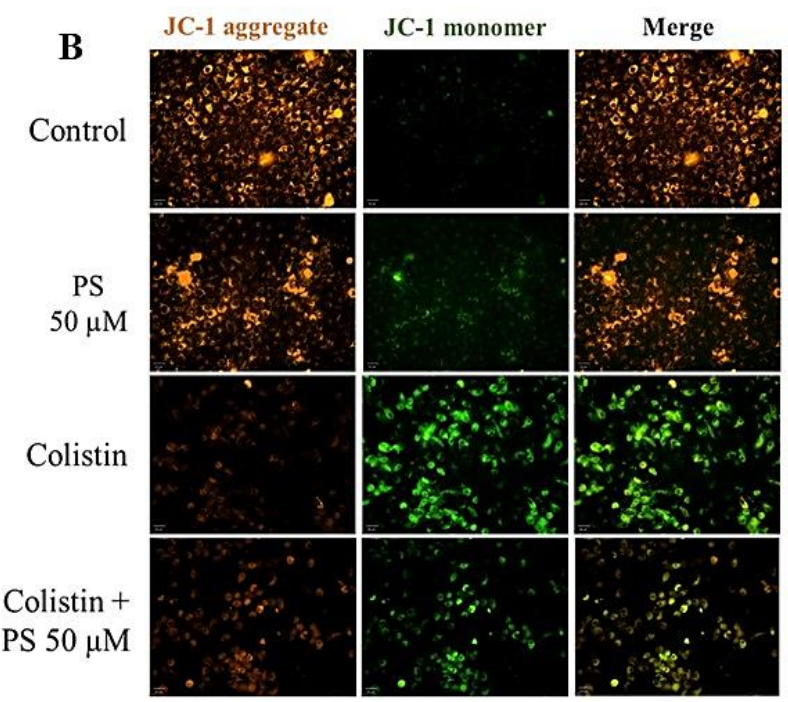

Figure 5. Effect of pinostrobin on colistin-induced reduction of mitochondrial membrane potential (MMP; $\psi_{\mathrm{m}}$ ). Alteration of mitochondrial membrane potential detected by JC- 1 staining of RPTEC/TERT1 cells after $24 \mathrm{~h}$ treated with $200 \mu \mathrm{g} / \mathrm{ml}$ colistin and $200 \mu \mathrm{g} / \mathrm{ml}$ colistin plus $50 \mu \mathrm{M}$ pinostrobin. (A) Fluorescence imaging of JC-1 aggregate form (represented normal MMP function; red color) and JC-1 monomeric form (represented damaged MMP; green color). (B) Quantitative analysis indicated the ratio between red and green fluorescence intensity. Decrease in the ratio was clarified as loss of $\psi \mathrm{m}$. The data are represented as mean \pm SEM of $\%$ control from $n=3-4$. ${ }^{*} P<0.001$ compared with control, ${ }^{\#} P<0.01$ compared with colistin-treated group. PS represents pinostrobin. 
A

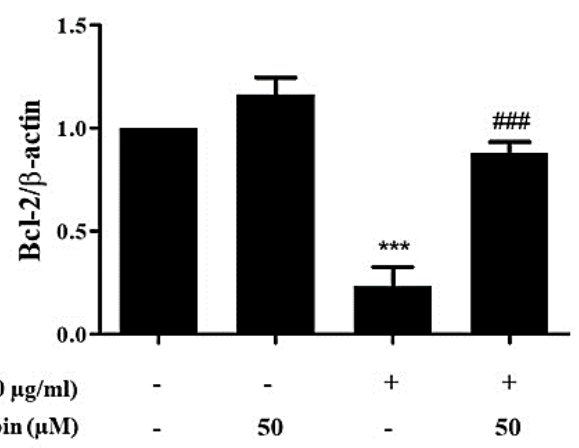

Colistin $(200 \mu \mathrm{g} / \mathrm{ml})$
Pinostrobin $(\mu \mathrm{M})$
B

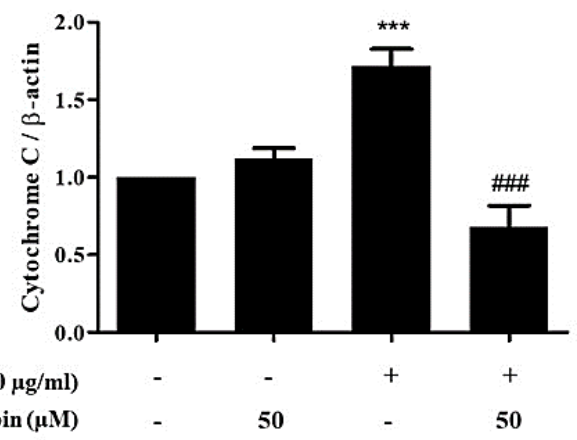

Colistin $(200 \mu \mathrm{g} / \mathrm{ml})$

Pinostrobin $(\mu \mathrm{M})$

Figure 6. Effect of pinostrobin on expression of apoptosis proteins in RPTEC/TERT1 cells. Protein expressions of Bcl-2 (A) and cytochrome c (B) normalized with $\beta$-actin are shown. The cells were treated with colistin with or without pinostrobin $(50 \mu \mathrm{M})$ for $24 \mathrm{~h}$ before protein extraction. The results are represented as mean \pm SEM of $\%$ control obtained from 3 experiments. ${ }^{*} P<0.001$ compared with control, ${ }^{\#} P<0.001$ compared with colistin-treated group. PS represents pinostrobin.

the percentage of cell death was analyzed by flow cytometry using annexin V-FITC/PI staining assay in RPTEC/TERT1 cells. Treatment of colistin $(200 \mu \mathrm{g} / \mathrm{ml})$ for $48 \mathrm{~h}$ significantly augmented early and late apoptosis compared with the control (Figure 3 ). As expected, co-treatment of pinostrobin $(50 \mu \mathrm{M})$ significantly attenuated apoptosis induced by colistin. Thus, these data suggest that pinostrobin can reduce colistin-induced cell apoptosis.

\subsection{Colistin-induced mitochondrial dysfunction is ameliorated by pinostrobin in renal proximal tubular cells}

Colistin induces cellular toxicity via stimulation of ROS production ${ }^{14}$. To examine whether pinostrobin reduced colistin-induced ROS levels, the effect of pinostrobin on ROS levels induced by colistin was determined using DCFH-DA assays. Incubating RPTEC/TERT1 cells with colistin significantly promoted higher cellular level of ROS compared with control cells. The ROS was significantly reduced when co-treated the cells with colistin and with $50 \mu \mathrm{M}$ pinostrobin (Figure 4). This data indicates that ROS-activated by colistin can be suppressed by pinostrobin. Next, the effect of pinostrobin on colistin-induced mitochondrial damage in RPTEC/ TERT1 cells was determined. As shown in Figure 5, colistin significantly decreased the ratio of red/green fluorescence intensity indicative of reduction in mitochondrial membrane potential $\left(\psi_{\mathrm{m}}\right)$. Co-treatment of colistin and pinostrobin significantly increased the ratio of red/green fluorescence intensity indicating that pinostrobin restore in mitochondrial membrane potential in RPTEC/TERT1 cells.

\subsection{Pinostrobin reduces cytochrome $\mathrm{C}$ and up-regulates anti-apoptotic Bcl-2 proteins expression}

Colistin induces cell apoptosis by releasing proapoptotic cytochrome c proteins from mitochondria to cytosol and reducing anti-apoptotic Bcl-2 protein expression ${ }^{9}$. Therefore, we explored the mechanism of pinostrobin on colistin-induced apoptosis in RPTEC/ TERT1 cells. Colistin significantly increased expression of cytochrome c, accompanied by reduction in Bcl-2 expression (Figure 6A and Figure 6B). As expected, cotreatment the cells with colistin and pinostrobin $(50 \mu \mathrm{M})$ reversed the expression of cytochrome $\mathrm{c}$ and $\mathrm{Bcl}-2$. Of note, treatment of pinostrobin alone had virtually no effect on cytochrome c and Bcl-2 expression. These data suggest that apoptotic proteins regulated by colistin were restored by pinostrobin.

\section{DISCUSSION}

Even though the use of colistin was limited due to the side effect associated with nephrotoxicity, this drug is still the last-line therapeutic option to treat MDR bacterial infection. Thus, development of nephroprotective agents to ameliorate renal injury is urgently needed. Previously, some therapeutic strategies including ascorbic acid ${ }^{20}$, baicalein ${ }^{21}$ or lycopene ${ }^{22}$ were introduced to relieve the undesirable effects of colistin. Whereas most of them showed protective effect of renal cells against colistin-induced toxicity in the in vitro and in vivo studies, none of the studies reported clinical utility 
of that compounds. Therefore, finding the novel natural products is important for identification of drug candidate beneficial for further drug development. In the present study, we revealed for the first time that pinostrobin protected renal cell toxicity induced by colistin. Pinostrobin is a chiral flavonoid found in B. rotunda harboring various pharmacological activities ${ }^{16-18}$. Our results are based on an immortalized epithelial cell line derived from human renal proximal tubule (RPTEC/ TERT1 cells) which express several key transporters useful for determination of xenobiotic transports ${ }^{23}$.

According to our preliminary results, colistin induced renal cell toxicity in concentration- and timedependent manner as analyzed by MTT assays in RPTEC/TERT1 cells. Colistin treatment at $200 \mu \mathrm{g} / \mathrm{ml}$ for 72 hours represents the most appropriate condition causing toxicity based on $\mathrm{IC}_{50}$ value. Amelioration of the cytotoxic effect of colistin was observed in the presence of pinostrobin. Concentration-response relationship demonstrated that maximal protective effect of pinostrobin on colistin-induced toxicity achieved at $50 \mu \mathrm{M}$ with no further response at higher concentration. Therefore, pinostrobin at $50 \mu \mathrm{M}$ was selected for further experiments. The protective effects of this compound were confirmed using flow cytometry. we observed that pinostrobin at $50 \mu \mathrm{M}$ reduced colistin-induced apoptosis with the similar level as noticed in MTT assays, suggesting that anti-apoptotic effects of pinostrobin completely explain the protective effects of pinostrobin. As mentioned in other studies, colistin-induced tubular cell apoptosis is mediated by oxidative stress production and mitochondrial damage ${ }^{14,15}$. Our data show that pinostrobin completely attenuated colistin-induced ROS level with the degree being higher than its anti-apoptotic effects. Therefore, reduction of ROS might not explain all anti-apoptotic mechanisms of pinostrobin. Of note, it is interesting to investigate the anti-oxidative mechanisms of pinostrobin which might be inhibition of ROS production or stimulation of ROS destruction. In addition, opening of mitochondrial permeability transition pore (mPTP) decreases mitochondrial membrane potential (MMP; $\Delta \psi_{\mathrm{m}}$ ) leading to mitochondrial dysfunction ${ }^{24}$. Our present study demonstrates that cotreatment with pinostrobin significantly attenuated the loss of MMP-induced by colistin which might be a partial mechanism of anti-apoptotic effects of pinostrobin.

Release of cytochrome c, a key protein regulating apoptosis cascade, from mitochondria is a consequence after MMP disruption ${ }^{25}$. In addition, pinostrobin prevented mitochondria damage induced by colistin supported by a decrease in cytochrome $\mathrm{c}$ protein expression following pinostrobin treatment. Upon the colistin treatment, pinostrobin not only suppressed the induction of proapoptotic cytochrome c protein level, but also restored an anti-apoptotic protein, Bcl-2. Taken together, the present study reveals the preventive effect of pinos- trobin on colistin-induced renal proximal tubular cell apoptosis. Although pinostrobin shows a potential agent for preventing of colistin-induced renal toxicity, the information concerning the pharmacological effects of pinostrobin needs further investigation in animal and human studies.

\section{CONCLUSIONS}

This study has demonstrated that pinostrobin shows a protective effect against colistin-induced apoptosis of human renal proximal tubular cells. The protective effect of pinostrobin is mediated by a decrease in oxidative stress and prevention of mitochondrial damage.

\section{ACKNOWLEDGEMENT}

This research was supported by the Thailand Science Research and Innovation (grant no. RSA6280082 to Sunhapas Soodvilai) and the International Research Network (IRN), Thailand Research Funds (grant no. IRN5804PHDW02 to Penjai Thongnuanjan). N.W. is supported by a research grant from the Development and Promotion of Science and Technology Talents Project (DPST).

\section{Conflict of interest}

The authors declare no conflict of interest.

\section{Funding}

The International Research Network (IRN), Thailand Research Funds (grant no. IRN5804PHDW02) and Thailand Science Research and Innovation (grant no. RSA6280082).

\section{Ethics approval}

None to declare.

\section{Article info:}

Received January 15, 2021

Received in revised form April 16, 2021

Accepted April 16, 2021

\section{REFERENCES}

1. Kaufman J, Dhakal M, Patel B, Hamburger R. Communityacquired acute renal failure. Am J Kidney Dis. 1991;17(2):191-8.

2. Stein J, Gottschall J, Osgood R, Ferris T. Pathophysiology of a nephrotoxic model of acute renal failure. Kidney Int. 1975;8: 27-41.

3. Bellomo R. The epidemiology of acute renal failure: 1975 versus 2005. Curr Opin Crit Care. 2006;12(6):557-60.

4. Nash K, Hafeez A, Hou S. Hospital-acquired renal insufficiency. Am J Kidney Dis. 2002;39(5):930-6.

5. Choudhury D, Ahmed Z. Drug-associated renal dysfunction and injury. Nat Clin Pract Nephrol. 2006;2(2):80-91.

6. Ordooei Javan A, Shokouhi S, Sahraei Z. A review on colistin nephrotoxicity. Eur J Clin Pharmacol. 2015;71(7):801-10. 
7. Bialvaei AZ, Samadi Kafil H. Colistin, mechanisms and prevalence of resistance. Curr Med Res Opin. 2015;31(4):707-21.

8. Aghapour Z, Gholizadeh P, Ganbarov K, Bialvaei AZ, Mahmood SS, Tanomand A, et al. Molecular mechanisms related to colistin resistance in Enterobacteriaceae. Infect Drug Resist. 2019;12:965-75.

9. Gai Z, Samodelov SL, Kullak-Ublick GA, Visentin M. Molecular mechanisms of colistin-induced nephrotoxicity. Molecules. 2019;24(3):653.

10. Lee TW, Bae E, Kim JH, Jang HN, Cho HS, Chang SH, et al. The aqueous extract of aged black garlic ameliorates colistininduced acute kidney injury in rats. Ren Fail. 2019;41:24-33.

11. Azad MAK, Sivanesan S, Wang J, Chen K, Nation RL, Thompson PE, et al. Methionine ameliorates polymyxin-induced nephrotoxicity by attenuating cellular oxidative stress. Antimicrob Agents Chemother. 2017;62(1):e01254-17.

12. Nilsson A, Goodwin RJ, Swales JG, Gallagher R, Shankaran H, Sathe A, et al. Investigating nephrotoxicity of polymyxin derivatives by mapping renal distribution using mass spectrometry imaging. Chem Res Toxicol. 2015;28(9):1823-30.

13. Ghlissi Z, Hakim A, Mnif H, Ayadi FM, Zeghal K, Rebai T, et al. Evaluation of colistin nephrotoxicity administered at different doses in the rat model. Ren Fail. 2013;35(8):1130-5.

14. Yousef JM, Chen G, Hill PA, Nation RL, Li J. Melatonin attenuates colistin-induced nephrotoxicity in rats. Antimicrob Agents Chemother. 2011;55(9):4044-9.

15. Lee EH, Kim S, Choi MS, Yang H, Park SM, Oh HA, et al. Gene networking in colistin-induced nephrotoxicity reveals an adverse outcome pathway triggered by proteotoxic stress. Int J Mol Med. 2019;43(3):1343-55.

16. Tewtrakul S, Subhadhirasakul S, Karalai C, Ponglimanont C, Cheenpracha S. Anti-inflammatory effects of compounds from Kaempferia parviflora and Boesenbergia pandurata. Food Chem. 2009;115(2):534-8.

17. Shindo K, Kato M, Kinoshita A, Kobayashi A, Koike Y. Analysis of antioxidant activities contained in the Boesenbergia pandurata Schult. Rhizome. Biosci Biotechnol Biochem. 2006; 70(9):2281-4.

18. Taechowisan T, Chanaphat S, Ruensamran W, Phutdhawong WS. Antibacterial activity of new flavonoids from Streptomyces sp. BT01; an endophyte in Boesenbergia rotunda (L.) Mansf. J Appl Pharm Sci. 2014;4(4):8-13.

19. Li C, Tang B, Feng Y, Tang F, Pui-Man Hoi M, Su Z, et al. Pinostrobin exerts neuroprotective actions in neurotoxin-induced parkinson's disease models through Nrf2 induction. J Agric Food Chem. 2018;66(31):8307-18.

20. Yousef JM, Chen G, Hill PA, Nation RL, Li J. Ascorbic acid protects against the nephrotoxicity and apoptosis caused by colistin and affects its pharmacokinetics. J Antimicrob Chemother. 2012;67(2):452-9.

21. Dai C, Tang S, Wang Y, Velkov T, Xiao X. Baicalein acts as a nephroprotectant that ameliorates colistin-induced nephrotoxicity by activating the antioxidant defense mechanism of the kidneys and down-regulating the inflammatory response. J Antimicrob Chemother. 2017;72(9):2562-9.

22. Dai C, Tang S, Deng S, Zhang S, Zhou Y, Velkov T, et al. Lycopene attenuates colistin-induced nephrotoxicity in mice via activation of the Nrf2/HO-1 Pathway. Antimicrob Agents Chemother. 2014;59:579-85.

23. Aschauer L, Carta G, Vogelsang N, Schlatter E, Jennings P. Expression of xenobiotic transporters in the human renal proximal tubule cell line RPTEC/TERT1. Toxicol in vitro. 2015; 30(1 Pt A):95-105.

24. Kowaltowski AJ, Castilho RF, Vercesi AE. Opening of the mitochondrial permeability transition pore by uncoupling or inorganic phosphate in the presence of $\mathrm{Ca}^{2+}$ is dependent on mitochondrial-generated reactive oxygen species. FEBS Lett. 1996;378(2):150-2.

25. Gottlieb E, Armour SM, Harris MH, Thompson CB. Mitochondrial membrane potential regulates matrix configuration and cytochrome c release during apoptosis. Cell Death Differ. 2003;10(6):709-17. 